\title{
SISTEM PENDUKUNG KEPUTUSAN PENENTUAN JENIS TANAMAN \\ PANGAN BERDASARKAN KANDUNGAN TANAH MENGGUNAKAN METODE ANALYTICAL HIERARCHY PROCESS (AHP) DENGAN ALGORITMA GENETIKA
}

\author{
Yuliani Indrianingsih, Winda Susyanti Naibaho \\ Program Studi Teknik Informatika \\ Sekolah Tinggi Teknologi Adisutjipto Yogyakarta \\ informatika@,stta.ac.id
}

\begin{abstract}
Samosir regency is a from North Sumatera province which dominantly people is live on agriculture. The most of the farmers using autodidact learning to determining the types of plants that will be process the appropriate with their land, where farmers just learn from their experiences and exchange opinion with another farmers. Based of the problem, the system will be built by Analytical Hierarchy Process (AHP) with Genetic Algorithm. The result of the testing from method Analytical Hierarchy Process (AHP) obtained result with consistency ratio values $<0,1$, which is -0,5936 while the result of the testing from Genetic Algorithm obtained value of the fitness is 157,25. Based on the test results, it can be concluded that the method Analytical Hierarchy Process (AHP) obtained the result more consistent with the value of consistency ratio should be 0,1 , so it will be easier to making decision, while on the analysis of Genetic Algorithm, obtained result are probabilistic as always having random process, so that decision making can not be consistent. So, Decision Support System to determination of plants based by contents of soil which are good and suitable is method Analytical Hierarchy Process (AHP).
\end{abstract}

Keywords : Analytichal Hierarchy Process (AHP), Genetic Algorithm, Food Plants.

\section{Pendahuluan}

Kabupaten Samosir merupakan salah satu kabupaten yang dominasi penduduknya hidup dari bercocok tanam. Banyaknya masyarakat petani Samosir yang masih belajar secara otodidak dalam penentuan jenis tanaman yang akan diolah mengakibatkan hasil panen pertanian tidak maksimal, sehingga dibutuhkannya suatu sistem yang dapat membantu agar hasil panen pertanian dapat lebih maksimal lagi

Berdasarkan permasalahan yang ada, maka dibangunlah sebuah system berbasis web yang mampu untuk menyelesaikan masalah tersebut. Sistem berbasis web ini dibangun dengan menggunakan metode Analytical Hierarchy Process (AHP) dan Algoritma Genetika. Dalam pembuatannya, system ini menggunakan jenis unsur hara sebagai criteria dan jenis tanaman sebagai alternatifnya, yang dimana nantinya system ini akan memberikan informasi kesesuaian tanaman yang akan diolah oleh masyarakat.

\section{Kajian Pustaka}

Sistem Pendukung Keputusan atau Decision Support System (DSS) merupakan system informasi interaktif yang menyediakan informasi, pemodelan dan manipulasi data. Sistem ini digunakan untuk membantu pengambilan keputusan dalam bentuk semi terstruktur dan situasi yang tidak terstruktur, dimana tak seorangpun tahu secara pasti bagaimana keputusan seharusnya dibuat. 


\section{Metode Penelitian}

\subsection{Metode Analytical Hierarchy Process (AHP) dengan, Algoritma Genetika}

Analytical Hierarchy Process (AHP) oleh dikembangkan oleh Thomas L. Saaty pada tahun 1980, merupakan proses dalam pengambilan keputusan dengan menggunakan perbandingan berpasangan (pairwase comparisons) untuk menjelaskan faktor revaluasi dan factor bobot dalam kondisi multi faktor. Beberapa prinsip dalam menyelesaikan permasalahan dengan Analytical Hierarchy Process (AHP), yaitu

1. Membuat hierarki

2. Menentukan prioritas elemen dengan membuat perbandingan berpasangan

Tabel 1 Skala Perbandingan Elemen

\begin{tabular}{|l|l|}
\hline $\begin{array}{l}\text { Intensitas } \\
\text { Kepentingan }\end{array}$ & \multicolumn{1}{c|}{ Keterangan } \\
\hline 1 & Kedua elemen sama pentingnya \\
\hline 3 & Elemen yang satu sedikit lebih penting daripada elemen yang lainnya \\
\hline 5 & Elemen yang satu lebih penting dari pada elemen yang lainnya \\
\hline 7 & Satu elemen jelas lebih mutlak penting dari pada elemen lainnya \\
\hline 9 & Satu elemen mutlak penting dari pada elemen lainnya \\
\hline $2,4,6,8$ & Nilai-nilai antara dua nilai pertimbangan yang berdekatan \\
\hline Kebaikan & $\begin{array}{l}\text { Jika untuk aktifitas i mendapat satu angka dibanding dengan aktifitas } \mathrm{j}, \\
\text { maka j mempunyai nilai kebaikannya dibanding dengan } \mathrm{i} .\end{array}$ \\
\hline
\end{tabular}

3. Sintesis

4. Mengukur Konsistensi

5. Menghitung Konsistensi Indeks/Consistency Index (CI)

$\mathrm{CI}=(\lambda \mathrm{maks}) / \mathrm{n}$

dimana: CI $=$ Consistency Index

$\mathrm{n} \quad$ = banyaknya elemen

$\lambda$ maks $=$ lamda maksimal

6. Menghitung Rasio Konsistensi/Consistency Ratio (CR)

$\mathrm{CR}=\mathrm{CI} / \mathrm{IR}$

dimana: $\mathrm{CR}=$ Consistency Ratio

$\mathrm{CI}=$ Consistency Index

IR = Index Random Consistency

Tabel 2 Nilai Indeks Random

\begin{tabular}{|l|l|}
\hline UkuranMatriks & Nilai IR \\
\hline 1,2 & 0,00 \\
\hline 3 & 0,58 \\
\hline 4 & 0,90 \\
\hline 5 & 1,12 \\
\hline 6 & 1,24 \\
\hline 7 & 1,32 \\
\hline 8 & 1,41 \\
\hline 9 & 1,45 \\
\hline 10 & 1,49 \\
\hline 11 & 1,51 \\
\hline
\end{tabular}




\begin{tabular}{|l|l|}
12 & 1,48 \\
\hline 13 & 1,56 \\
\hline 14 & 1,57 \\
\hline 15 & 1,59 \\
\hline
\end{tabular}

7. Memeriksa Konsistensi Hirarki dengan nilai Consistency Ratio kurang atau sama dengan 0,1 .

\subsection{Algoritma Genetika}

Algoritma genetika pertama kali diperkenalkan oleh seorang professor psikologi dan ilmu computer yaitu John H. Holland (1975). Algoritma genetika adalah algoritma pencarian heuristik yang didasarkan atas mekanisme evolusi biologis. Beberapa tahapan yang diperlukan di dalam Algoritma Genetika, yaitu :

1. Inisialisasi populasi awal

2. Evaluasi nilai fitness

Setiap gen yang merepresentasikan tanaman memiliki nilai dari setiap kriteria

Nilai $=\sum(\mathrm{Bi} * \mathrm{Ki})$

Dimana :

$\mathrm{Bi}=$ Bobot criteria ke-i

$\mathrm{Ki}=$ Kriteria ke-i

Fitness yaitu rata-rata dari total jumlah nilai semua tanaman yang dikalikan dengan bobotnya

Fitness $=\frac{n * \text { Nilai }_{n}+(\mathrm{n}-1) * \text { Nilai }_{1}+\cdots+\text { Nilai }_{n-1}}{n}$

3. Untuk mencapai maksimum generasi

a. Seleksi

Metode seleksi yang digunakan adalah seleksi Roda Roulette (Roulette Wheel Selection)

- Hitung total fitness $(\mathrm{F})$

TotFitness $=\sum F_{k} ; \quad \mathrm{k}=1,2, \ldots$, popsize

- Hitung fitness relatif tiap individu

$P_{k}=\frac{F_{k}}{\text { TotFitness }}$

- Hitung fitness komulatif

Dimana :

$q_{1}=p_{1}$

$q_{k}=q_{k-1}+p_{k} ; \quad \mathrm{k}=2,3, \ldots$, popsize

- Pilih induk yang akan menjadi kandidat untuk disilangkan (crossover) dengan cara bangkitkan bilangan random $\mathrm{r}$. Jika $q_{k} \leq \mathrm{r}$ dan $q_{k-1}>\mathrm{r}$, maka pilih kromosom ke $(\mathrm{k}+1)$ sebagai kandidat induk.

b. Crossover

Perkawinan silang (crossover) dilakukan atas dua kromosom dari orang tua yang terpilih pada proses seleksi untuk menghasilkan kromosom anak (offspring).

c. Mutasi

Mutasi ini berperan untuk menggantikan gen yang hilang dari populasi akibat proses seleksi yang memungkinkan munculnya kembali gen yang tidak muncul pada inisialisasi populasi.

d. Lakukan evaluasi fitness setiap individu pada P' (generasi)

e. Bentuk populasi baru : P (generasi) $=\left\{\mathrm{P}\right.$ (generasi-1) yang survive, $\mathrm{P}^{\prime}$ (generasi) $\}$. 


\subsection{PERANCANGAN APLIKASI}

\subsubsection{Diagram Konteks}

Diagram konteks dibuat untuk menggambarkan sumber serta tujuan data yang akan diproses atau dengan kata lain diagram tersebut digunakan untuk menggambarkan system secara umum/global dari keseluruhan sistem yang ada.

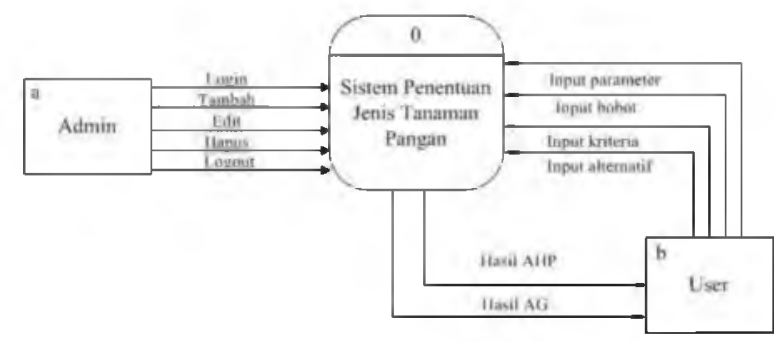

Gambar 1 Diagram Konteks

\subsubsection{DAD Level 0}

DAD level 0 merupakan tahapan proses yang ada di dalam diagram konteks, yang penjabarannya lebih terperinci.

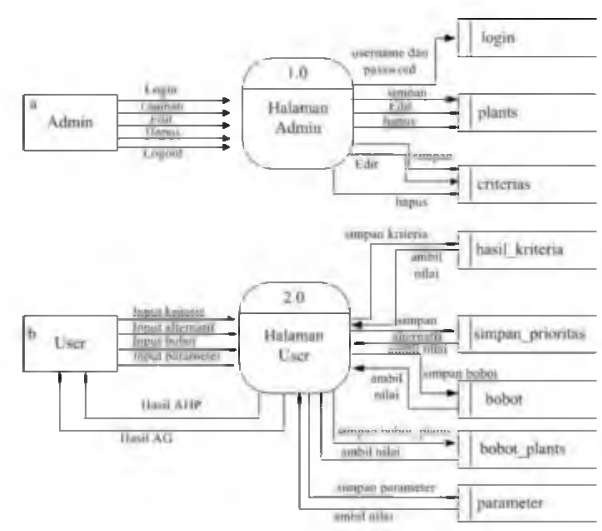

Gambar 2 DAD Level 0

\subsubsection{DAD Level 1 Proses Admin}

DAD level 1 proses admin merupakan penjabaran bagian admin terhadap sistem yang ada. Admin dapat melakukan proses manipulasi data yang akan mendukung proses sistem user. 


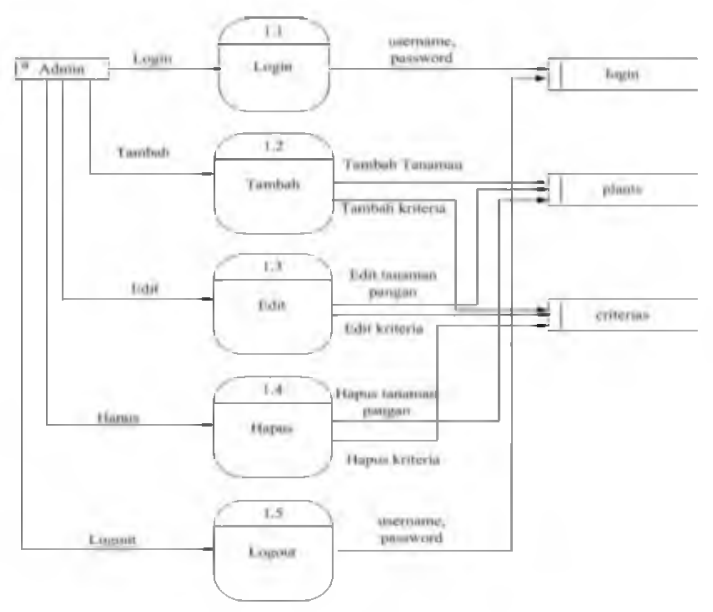

Gambar 3 DAD Level 1 Proses Admin

\subsubsection{DAD Level 1 Proses $U$ ser}

DAD level 1 Proses Use ini merupakan penjabaran bagian user. Dalam proses ini, user yang sebagai pengguna dalam pengujian system akan menginputkan nilai unsur hara yang akan diproses oleh sistem. Setelah itu, hasil perhitungan akan dikembalikan kepada user sebagai output (keluaran) dalam bentuk grafik untuk mengetahui keputusan akhir yang diberikan oleh sistem.

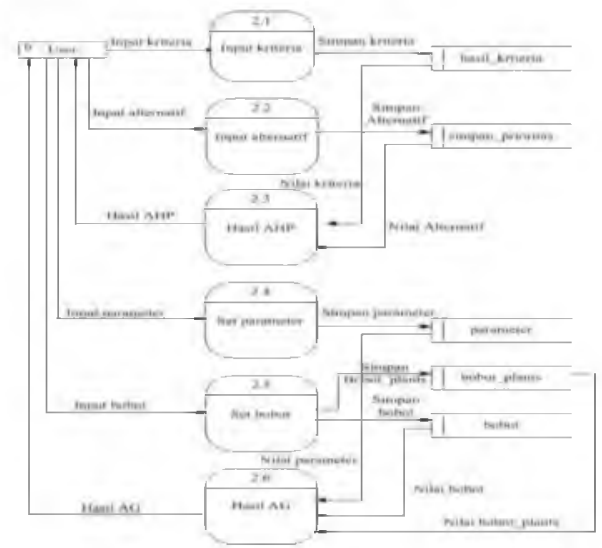

Gambar 4 DAD Level 1 Proses User

\subsubsection{Flowchart Program User}

Flowchart program user merupakan gambaran yang mendeklarasikan alur program yang terdapat pada bagian user (pengguna). 


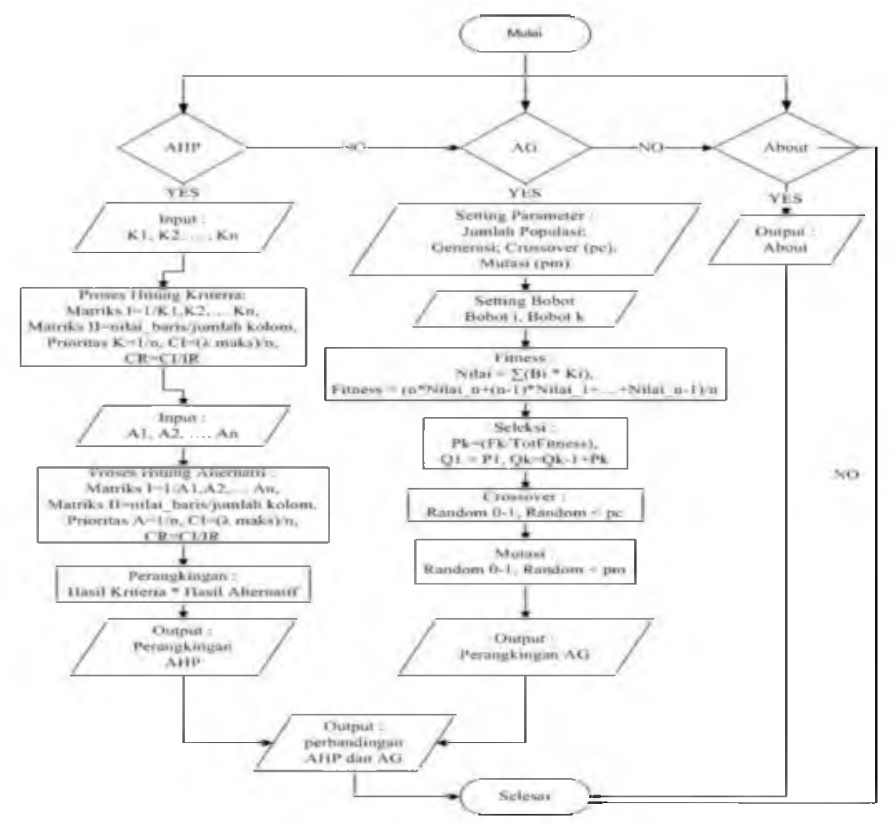

Gambar 5 Flowchart Program User SPK Tanaman Pangan

\section{Hasil Dan Pembahasan}

\subsection{Halaman Kriteria AHP}

Halaman Kriteria AHP merupakan halaman yang berfungsi untuk memasukkan nilai perbandingan yang akan dihitung

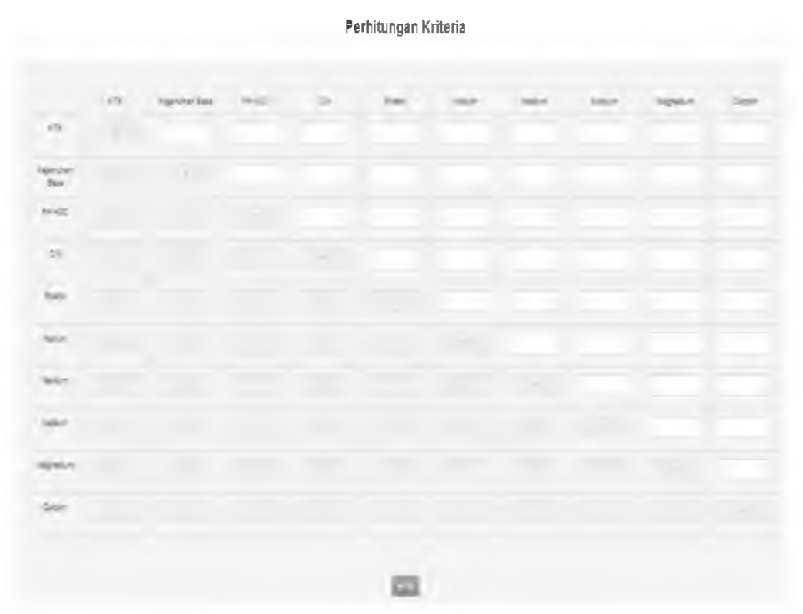

Gambar 6 Halaman Kriteria AHP

\subsection{Halaman Alternatif AHP}

Halaman Alternatif AHP merupakan halaman yang digunakan untuk menghitung nilai-nilai alternative berdasarkan kriteria - kriteria yang sudah ada. 


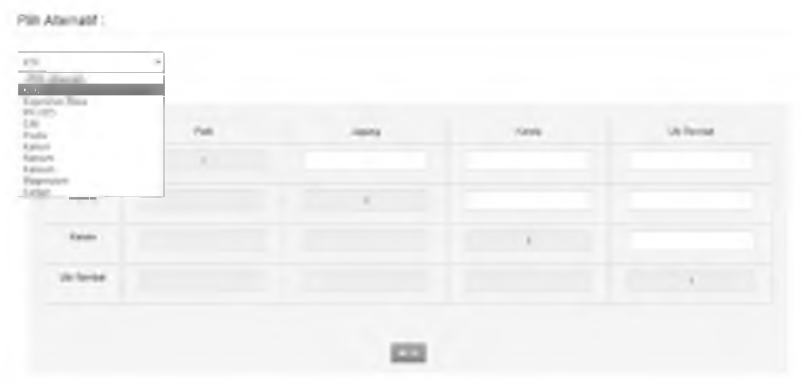

Gambar 7 Halaman Alternatif AHP

\subsection{Halaman Hasil AHP}

Halaman Hasil AHP merupakan halaman yang berfungsi untuk menampilkan hasil akhir dari proses perhitungan AHP.

$$
\text { Chart AHP }
$$

Hasil Perhitungan AHP

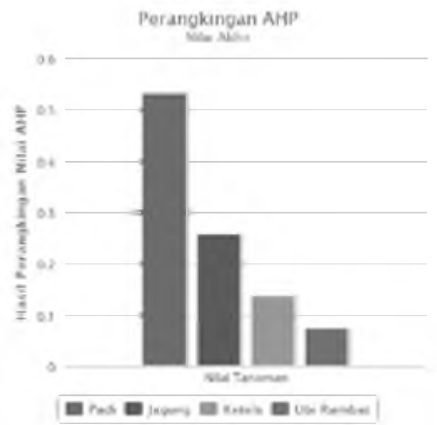

\begin{tabular}{|c|c|c|c|c|c|c|c|c|c|c|c|}
\hline Allemalif & KTK & หejenutan Вақа & P: $H 20$ & CNN & Posfor & Kalium & Natrium & Kalsium & Magnesium & Carbon & Hasil \\
\hline Illa Kritena & 01255 & 0.1883 & 017866 & 01044 & 00647 & 01316 & 00992 & 00618 & 00226 & 00243 & \\
\hline Padi & 06128 & 0.5531 & 05708 & 05529 & Q 4824 & 04824 & 01650 & 0 1658 & 05579 & 04824 & 05322 \\
\hline Jagung & 02551 & 0.2448 & 02289 & 02729 & 02718 & 02748 & 02772 & o 2772 & 02633 & 02718 & 02577 \\
\hline Ketella & 00687 & 0.1273 & 01961 & 01276 & 01575 & 01575 & 01611 & 01611 & 01219 & 01575 & 01736 \\
\hline UGi Rambal & 0.0435 & 0.0748 & 0.0642 & 0.0667 & 0.0893 & 0.0893 & 01096 & 0.096 & 0.0569 & 0.0839 & 0.0741 \\
\hline
\end{tabular}

Gambar 8 Halaman Hasil AHP

\subsection{Halaman Set Parameter AG}

Halaman Set Parameter AG merupakan halaman yang digunakan untuk menentukan parameter dari algoritma genetika, yang menggunakan ukuran populasi, maksimum generasi, probabilitas crossover dan probabilitas mutasi sebagai parameternya.

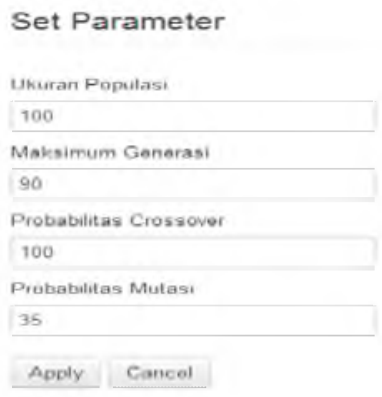

Gambar 9 Halaman Set Parameter AG

\subsection{Halaman Set Bobot AG}

Halaman Set Bobot AG merupakan halaman yang digunakan untuk menentukan bobot dari algoritma genetika. 


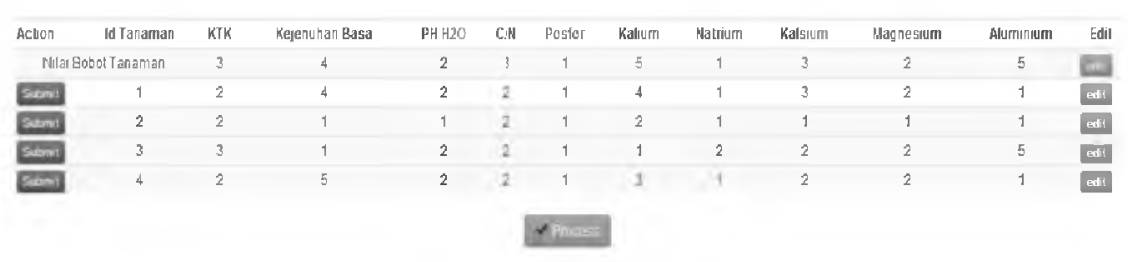

Gambar 10 Halaman Set Bobot AG

\subsection{Halaman Hasil Algoritma Genetika}

Halaman Hasil Algoritma Gennetika merupakan halaman yang menampilkan perhitungan agoritma genetika secara detail.

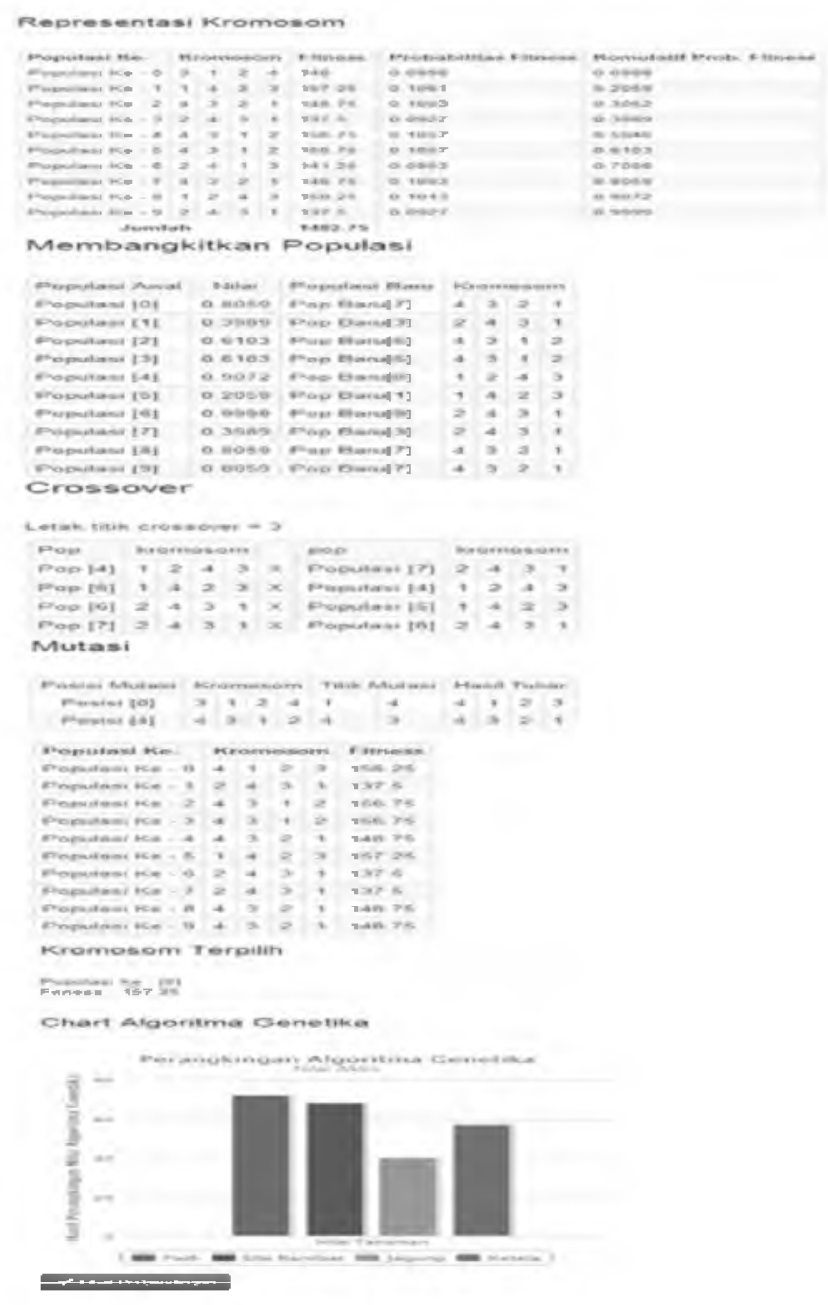

Gambar 11 Halaman Hasil Algoritma Genetika

\subsection{Halaman Perbandingan Metode}

Halaman Perbandingan Metode merupakan halaman yang menampilkan perbandingan hasil perhitungan akhir kedua metode, yaitu AHP dan Algoritma Genetika. 

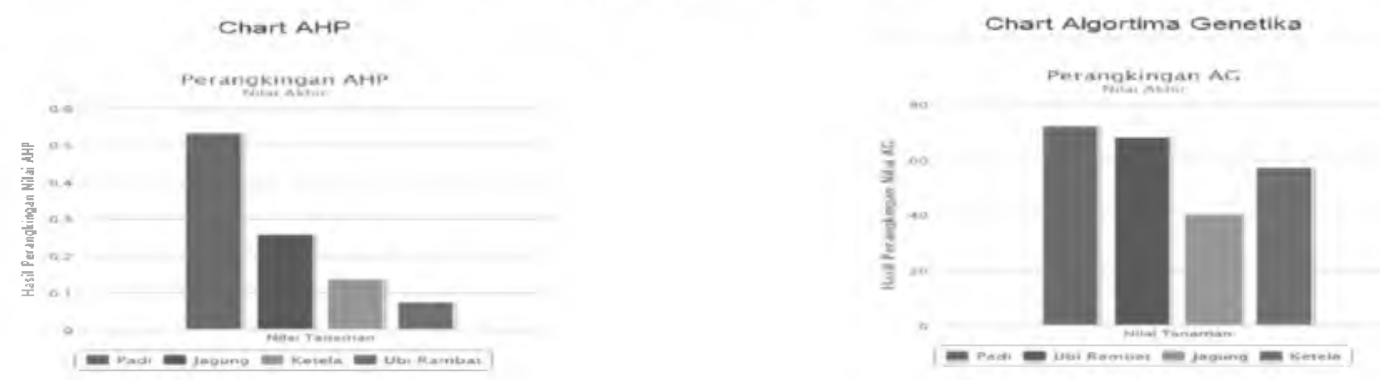

Gambar 12 Halaman Perbandingan Metode 
4.8 Perhitungan Manual dengan Perhitungan Sistem AHP

Tabel 3 Analisa Perhitungan Manual AHP

\begin{tabular}{|l|c|c|c|c|ccc|c|c|c|c|}
\hline & KTK & $\begin{array}{c}\text { Kejenuhan } \\
\text { Basa }\end{array}$ & $\begin{array}{c}\text { PH } \\
\text { H2O }\end{array}$ & C/N & Posfor & Kalium & Natrium & Kalsium & Magnesium & Carbon & Hasil \\
\hline Nilai & 0,1255 & 0,1883 & 0,1786 & 0,1044 & 0,0647 & 0,1316 & 0,0982 & 0,0618 & 0,0226 & 0,0243 & \\
\hline Padi & 0,6128 & 0,5531 & 0,5708 & 0,5329 & 0,4824 & 0,4824 & 0,4658 & 0,4658 & 0,5579 & 0,4824 & 0,5322 \\
\hline Jagung & 0,2551 & 0,2448 & 0,2289 & 0,2729 & 0,2718 & $\mathbf{0 , 2 7 1 8}$ & 0,2772 & 0,2772 & 0,2633 & 0,2718 & 0,2577 \\
\hline Ketela & 0,0887 & 0,1273 & 0,1361 & 0,1276 & 0,1575 & $\mathbf{0 , 1 5 7 5}$ & 0,1611 & 0,1611 & 0,1219 & 0,1575 & $\mathbf{0 , 1 3 6}$ \\
\hline Ubi Rambat & 0,0435 & 0,0748 & 0,0642 & 0,0667 & 0,0883 & $\mathbf{0 , 0 8 8 3}$ & 0,096 & 0,096 & 0,0569 & 0,0883 & 0,0741 \\
\hline
\end{tabular}

Hasil Perhitungan AHP

\begin{tabular}{|c|c|c|c|c|c|c|c|c|c|}
\hline Altematif & KTK & Kejenuhan Basa & PH H2O & $C / N$ & Postor & Kalium & Natrium & Kalsium & Magnesium \\
\hline Nilai Kriteria & 01255 & 01883 & 01786 & 01044 & 00647 & 01316 & 00982 & 00618 & 00226 \\
\hline Padi & 06128 & 0.5531 & 05708 & 05329 & 04824 & 04824 & 04658 & 04658 & 05579 \\
\hline Jagung & 02551 & 02448 & 02289 & 02729 & 02718 & 02718 & 02772 & 02772 & 02633 \\
\hline Ketela & 00887 & 01273 & 0 1361 & 0.1276 & 0.1575 & 01575 & 0 1611 & o 1611 & 01219 \\
\hline Uby Rambat & 00435 & 0.0748 & 00642 & 00667 & 00883 & 00883 & 0096 & 0096 & 00569 \\
\hline
\end{tabular}

4.9 Perhitungan Manual dengan Perhitungan Sistem Algoritma Genetika

Tabel 4 Analisa Perhitungan Manual Algoritma Genetika

\begin{tabular}{|c|c|c|c|cc|}
\hline Populasi Ke- & \multicolumn{2}{|c|}{ Kromosom } & \multicolumn{2}{c|}{ Fitness } \\
\hline PopulasiKe - 0 & 4 & 1 & 2 & 3 & 156,25 \\
\hline PopulasiKe - 1 & 2 & 4 & 3 & 1 & 137,5 \\
\hline PopulasiKe - 2 & 4 & 3 & 1 & 2 & 156,75 \\
PopulasiKe - 3 & 4 & 3 & 1 & 2 & 156,75 \\
PopulasiKe - 4 & 4 & 3 & 2 & 1 & 148,75 \\
PopulasiKe-5 & $\mathbf{1}$ & $\mathbf{4}$ & $\mathbf{2}$ & $\mathbf{3}$ & $\mathbf{1 5 7 , 2 5}$ \\
\hline PopulasiKe - 6 & 2 & 4 & 3 & 1 & 137,5 \\
\hline PopulasiKe - 7 & 2 & 4 & 3 & 1 & 137,5 \\
\hline PopulasiKe - 8 & 4 & 3 & 2 & 1 & 148,75 \\
\hline PopulasiKe - 9 & 4 & 3 & 2 & 1 & 148,75 \\
\hline
\end{tabular}




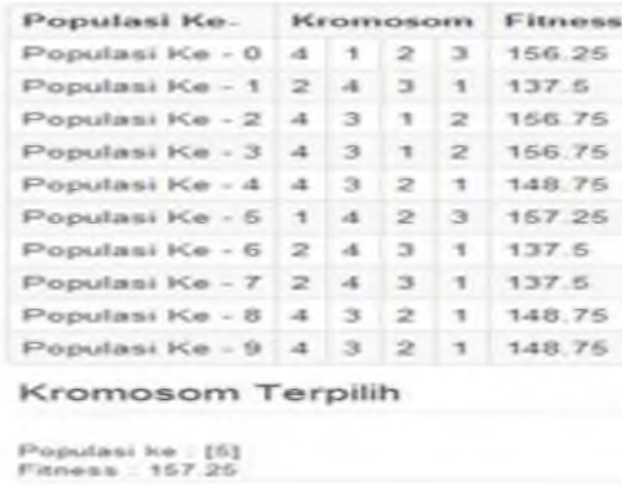

\subsection{Hasil Perbandingan AHP dengan Algoritma Genetika}

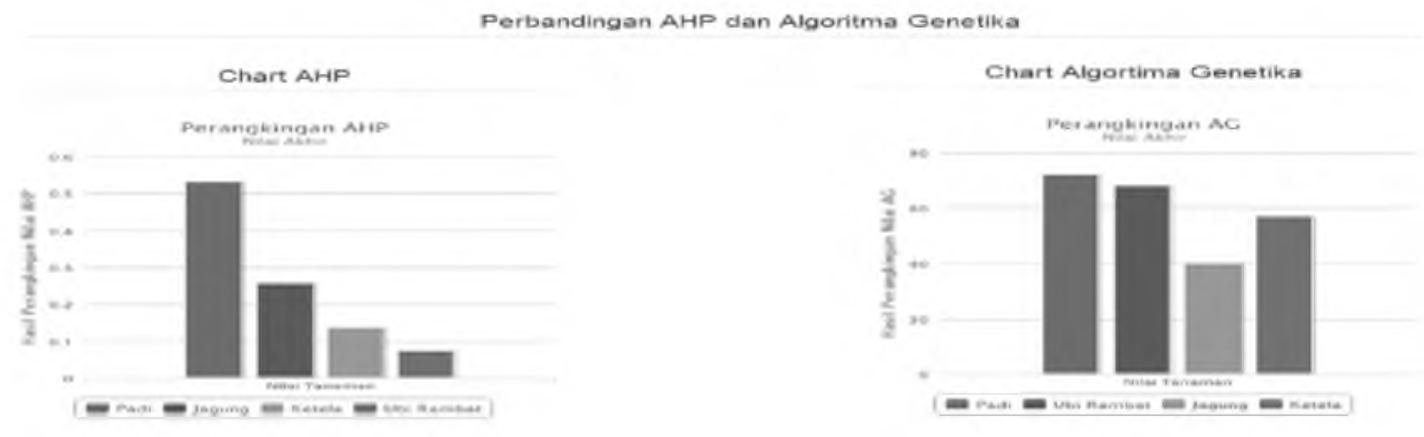

Gambar 13 Hasil Perbandingan AHP dengan Algoritma Genetika

\section{Penutup}

\subsection{Kesimpulan}

Dari hasil penelitian yang telah dilaksanakan, maka dapat diambil kesimpulan, yaitu :

1. Sistem dapat menentukan jenis tanaman yang cocok berdasarkan kandungan unsur hara yang dimasukkan

2. Jenis tanaman yang sudah diujicoba suda hproduktif pada kandungan unsur hara yang diujikan

3. Berdasarkan hasil pengujian, maka metode Analitychal Hierarchy Process (AHP) dan Algoritma Genetika dapat diterapkan pada system pendukung keputusan penentuan tanaman pangan ini. Pada metode AHP diperoleh hasil dengan nilai rasio konsistensi $<0,1$, yaitu 0,5936, sedangkan pada Algoritma Genetika diperoleh hasil dengan nilai fitness 157,25. Pada metode Analitychal Hierarchy Process (AHP) diperoleh hasil yang lebih konsisten dengan nilai rasio konsistensi harus $<0,1$ sedangkan pada Algoritma Genetika tidak sebaik Analitychal Hierarchy Process (AHP) yang selalu memberikan hasil konsisten karena Algoritma Genetika memiliki kelemahan yang selalu berhubungan dengan bilangan random sehingga hasilnya bersifat probabilistik. Jadi, Sistem Pendukung Keputusan Penentuan Jenis Tanaman Pangan Berdasarkan Kandungan Tanah yang baik dan sesuai adalah metode Analitychal Hierarchy Process (AHP).

\subsection{Saran}

Melalui analisis system maka dapat diketahui bagaimana cara kerja sistem, sehingga didapatkan saran-saran untuk pengembangan ke depannya agar tercipta sistem yang lebih maksimal dan efisien, yaitu :

1. Sistem dilakukan juga untuk pengujian tanaman-tanaman yang lain

2. Menambah criteria tanaman (unsur hara) agar hasil yang diberikan system lebih optimal 
3. Membuat tampilan yang lebih rapi dan sederhana (user friendly) agar lebih mudah digunakan oleh $u$ ser.

\section{Daftar Pustaka}

Husni, Imam. 2010. Sistem Informasi Pendukung Keputusan Pada Seleksi Penerimaan Pegawai Menggunakan Metode Analytical Hierarchy Process (AHP)

Kusrini. 2007. Konsep dan Aplikasi Sistem Pendukung Keputusan. Yogyakarta.Andi Offset

Kusumadewi, Sri \&Purnomo, Hari.2005.Penyelesaian Masalah Optimasi Menggunakan TeknikTeknik Heuristik. Yogyakarta. Graha Ilmu

Sutedjo. MulMulyani. Kartasapoetra, A.G. 2005.Pengantar Ilmu Tanah, Jakarta, Rineka Cipta

Perdana, Ari Satria. 2013. Sistem Pendukung Keputusan Pemilihan Jenis Laptop Dengan Menggunakan Metode Analytical Hierarchy Process

Raharjo, Budi. 2011. Belajar Otodidak Pemrograman Web dengan PHP + Oracle. Bandung. Informatika Bandung

Sumartini Dana. Purnomo Budi Santoso dan D. J. Djoko H. S. 2012. Sistem Pendukung Keputusan Pengobatan Penderita Diabetes Menggunakan Integrasi Decision Table Dan Algoritma Genetika.Jurnal EECCIS Vol.6, No.1 